\title{
Commonplace
}

\section{How to be Angry on the Internet (Mindfully), Part 2}

\section{Diane Grimes}

Published on: Aug 10, 2020

DOI: $10.21428 / 6 \mathrm{ffd} 8432 . \mathrm{cff} 9 \mathrm{fef} 6$

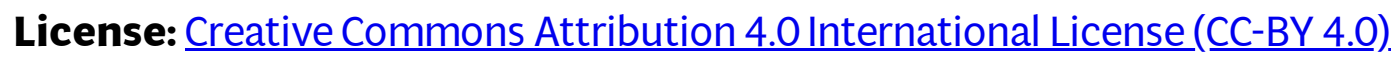


This article is actually two articles. Part 1 is written by Whitney Phillips; Part 2 is written by Diane Grimes. Phillips is a media studies scholar who explores how and why polluted information spreads online. Grimes is an organizational communication scholar who explores contemplative communication practices. Our argument across both pieces is that mindfulness-which has been shown to improve anxiety and depression symptoms, is used to treat PTSD symptoms, and can enhance interpersonal communication offline-is directly applicable to online contexts as well. Not without some additional context, however, given the unique contours (and challenges) of socially networked spaces. So, we're tackling network considerations first, actual mindfulness practices second.

Throughout both parts (Part 1 is available here), we'll be focusing on the experience and expression of anger. We've chosen to spotlight anger for two basic reasons. First, there's just so much of it online-a reflection of the fact that lots of different emotions, from anxiety to shame to hurt, transform into anger because anger is easier to feel. It's older, simpler, and provides at least a sense of satisfaction when we project our frustrations outward (although that satisfaction rarely lasts for long). The second reason we're focusing on anger is that mindfulness is often framed as incompatible with anger. If you're mindful, you stay calm and unemotional; anger is a sign that you're doing it wrong. That's not true. Anger is critical to cultivating a more just society, and is part of a healthy emotional landscape. What we need isn't to eradicate anger, but rather, to use anger mindfully - a balance that's tricky to achieve in embodied spaces, and even more so online, given the complexities of network contours and affordances. This balance is, however, possible, and increasingly critical as we barrel towards the 2020 election and all the uncertainty after. So let's get mad, but mindfully.

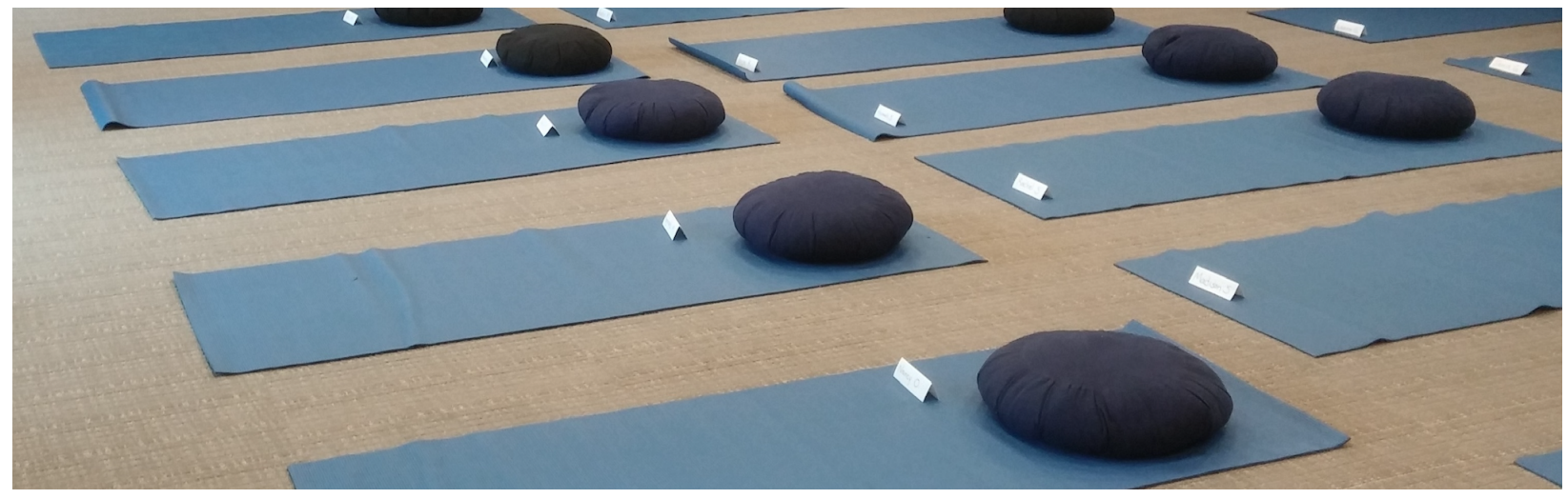

Three rows of blue yoga mats, each with a blue or black meditation cushion on it and name card

When we're feeling threatened, our Lizard Brain goes into a fight/ flight/ freeze mode because its job is to assess threats and tell us whether or not we're safe. This comes from a good evolutionary place but can backfire and therefore not actually help in online contexts. So, here in Part 2, we're going to talk 
about ways to counteract the Lizard Brain and respond mindfully to angering things instead of reacting.

There are of course actual immediate dangers online; see this chart for the kinds of threats that exist and can be devastating. We're not saying that when someone is directly threatening your life, you just need to relax and start meditating! When this happens, what we need to do is get ourselves somewhere safe. Here are some resources that may be helpful should you find yourself in that kind of situation.

The 4As in Part 1 are critical to assessing what's actually happening on social media, which isn't always what appears to be happening (remember, observation is not confirmation online); doing this "zoom out" to the wider media environment helps us understand what it is we're looking at, and therefore, how to respond in the most targeted, efficient, ecologically-informed way possible. This includes determining what the threats are, where they're coming from (if that's possible to know) and what we can or should do about them. Those 4As are also critical when confronted by other kinds of perhaps less immediately dangerous but still deeply infuriating content; taking a moment to consider network influences and affordances is its own kind of mindfulness, one specifically calibrated to online environments. Doing that helps create space for the more traditional mindfulness practices we'll be describing here. The underlying argument is that we don't have to be swept away by anger online; instead we can recognize that bit of time/space between the impulse to act and actually taking actionand then use that time/space to make a wise decision and create a more skillful response. What we want to avoid is reactivity, not the experience of anger itself, a point Lama Rod Owens also emphasizes - not only does reactivity hinder our response in the moment, it can cause chronic over-activation and stress, which creates a broad blockage to skillful action online. There are three basic questions to consider which help guide our mindfulness practices and direct us to a more skillful place when we're angry online:

1) How do we understand, observe, and assess our own reactions or responses when we start to get a reaction to something that has us feeling threatened (I call that reaction "going over the cliff")? 2) How do we work with appropriate anger? 3) What about positive events; where do they fit in the picture?

To answer question 1: We want to say up front that we're not here to judge whatever sends you over the cliff. We're here to work with reactions, whatever their cause may be. Whether you're full of righteous anger (which we discuss below) or fighting for justice, whether tiny slights send you over the cliff or you find yourself reacting constantly to something that others find silly, working to turn reactions to responses is wise either way. 
So how can we deal with reactions that arise for whatever reason? When we're new to paying attention to our reactions, it's helpful to simply recognize it as a reaction and wait for all the relevant information to reach the neocortex, then responding in whatever way the neocortex suggests. This is what they used to call "counting to 10." Or "taking a deep breath." And it's way better than cussing someone out on Twitter/punching your boss. When you have a little more experience with noticing reactions , another strategy is to start to pay attention to your patterns - what seems to always send you over the cliff? Thich Nhat Hanh has a relevant way. of talking about this. He says when you are angry, it's like when a baby is crying. You don't throw away the whole baby! You look into the situation. What is causing the reaction? Is the baby's diaper wet? Is the baby hungry? Do they want to be picked up? We can look into our anger the same way and figure out what is causing it. Then over time you can start to approach your amazingly predictable response to that anger trigger with kindness and even with a sense of humor, catching yourself before you go tumbling over the cliff.

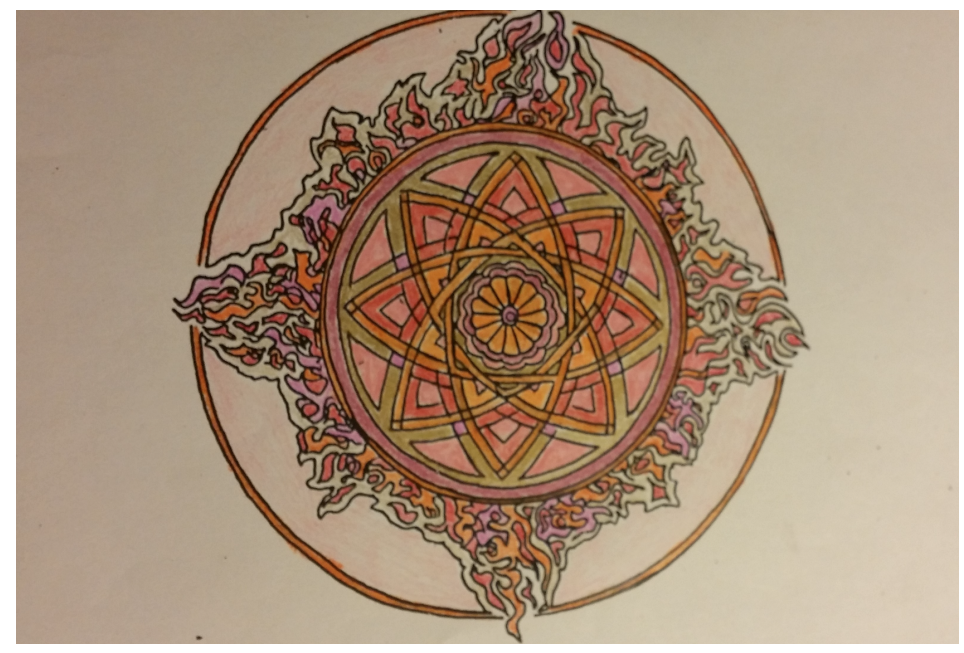

Pink orange red green mandala surrounded by pink orange red flames with a thin orange circle touching the outermost corners of the flames. One way to mull over the cause of your anger is to work on a mandala, in this case a fiery anger mandala! Here are some printable pages or you could do it online

When you have even more experience noticing reactions and noticing your anger patterns, you can start paying close attention to what your body is doing early in the process. When the trigger occurs, do you literally start to "see red"? Does your stomach start to hurt? Or maybe your chest gets tight? You can teach yourself to notice when that reaction is just starting and head it off before it does. And still know that if the reaction does occur, it's got to play itself out so you're back to your wait-it-out strategy. There's something called a refractory period that happens after the reaction gets going, and no new information is going to get into that Lizard Brain of yours during that time. Thus, walk away from your computer, call a time-out, pretend your phone has died, and wait; don't be at the mercy of your old 
patterns (which, think about it, is what's left after no new information can get in). You won't make good decisions, solve the world's many problems, or do anything to improve your relationships in that state.

Question 2 suggests there are times when it is important and helpful to be angry. Righteous anger might be exactly the correct response as Black feminist Audre Lorde argues in "The Uses of Anger." Even then it's better to keep your wits about you. You want to be able to respond to the injustice rather than being triggered and reacting unthinkingly, as Part 1 makes clear. In tense situations, in volatile situations, in situations where others are reacting rather than responding, where you're being goaded or taunted, keeping awareness of your body, of your patterns, and responding in the way you choose is better. Hopefully it's clear that none of this is suggesting that emotions are bad or wrong or make us weak. In fact, they're very helpful as they give us needed information. Like with the "anger baby," we can look beneath the surface of that needed information. Is hurt underlying anger because anger seems easier to express? Is sadness or anxiety hidden under anger? Or is anger hidden, expressed perhaps as annoyance or subtle disconnection?

Especially when seeking justice or working across differences, know too that rationality can be a trap. For one, don't buy into making emotion the opposite of rationality. Realize that what seems rational is based on a person's often taken-for-granted assumptions and perspective. You may (try to) be objective but it's in a smaller sense - in a larger sense, the questions a journalist thinks to ask, the way a researcher sets a study up, already shapes what can be learned. All the -isms are already baked in; what is "neutral" is often the white male upper-middle class cis straight-acting way of seeing. The questions, study, argument of a member of any other group is often suspect because it represents "special interests." One small group (and perhaps a few that play along) is seen as objective, neutral and rational. But Sandra Harding suggests we go in a different direction-where we uncover and acknowledge and tell our audience about-our assumptions so they can better make sense of and evaluate our work. It's always wise to ask the question "Rational for whom?"

Question 3, which reminds us that evolution really only cares that we survive long enough to reproduce and start the next generation, asks what do we do when we realize our brain does not care much about positive events? Even though we think we care about happiness above all else, our brains actually aren't as interested in things that make us feel happy/good/safe because there's no survival value in it. For example, imagine that you pass someone in the hall and they don't speak. Our Lizard Brain starts waking up-Have you done something horrible that you're not aware of? Is this person angry at you? Do they know you were complaining about them to your friend just yesterday? Or fill in the blank with your own scenario. It may immediately affect your mood; you may worry about it the rest of the day; you may get angry; you might investigate to try to figure out what happened; did the person just not see you, or did they actually ignore you? 
Now imagine that same person passes you in the hall and, instead of not speaking, they smile and say hi. Unless they're your secret crush, that's not going to stay with you all day, maybe not even beyond the moment. So, what can we do? Notice and enjoy. Bring yourself into your body, into the present moment so you can fully experience it. There's enough to be worried, scared and angry about; enjoy the pleasant moments when they present themselves.

In the next section, I'll begin with the benefits of simple practices for each of the three questions and provide links to the practices. Then I'll explain why a consistent sitting meditation practice is also helpful for working with the three questions, and end with a short set of meditation instructions.

\section{Practices and their Benefits}

\section{Question 1 (Reactions and Triggers): Body Scan}

To work with our reactions or triggers, as mentioned above, it's helpful to be aware of what is happening in our bodies. There are at least three reasons to do this: First, maybe we're not fully aware of how terrible our bodies feel or what the exact terribleness is when we go "over the cliff." Maybe our fists or teeth are clenched. Maybe our stomach or chest is tight. In the moment, it's useful to notice because noticing might convince us that we don't want to feel that way. Then we may decide to do something about it. Second, to learn to prevent ourselves from going over the cliff, we have to be aware of subtle changes in our body. Through body scans we teach ourselves to notice more.

Third, body scans help us realize how much of that chronic tension we are always carrying. Basically, body scans direct you to pay attention to each part of your body in turn, noticing any sensation you feel there (or whether you feel no sensation). It's important to note that body scans are not primarily to get us to relax but to help us notice. There are lots of guided body scans online, of varying lengths. Here's

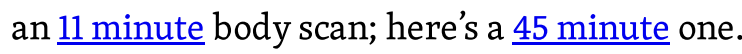

\section{Question 2 (Righteous Anger): Just like me practice}

Righteous anger = righteously kick some ass, yes? What follows is counterintuitive but might be helpful. Whether it's an individual, or a policy and you're angry at those who created and supported it, or a system and you're mad that those who benefit from it, those not working to change it (or those who enthusiastically uphold it), seeing them as people "just like you" can clear your energy to take needed action. Thich Nhat Hanh talks about this in his video above. 
This might seem like a heavy/unfair burden to place on marginalized folks in particular when they're being oppressed/threatened by bigots and other reactionaries. Rod Owens discusses a variation of this practice in an interview with Tara Brach and addresses this exact point: by extending compassion/acknowledgment of someone's humanity, that doesn't mean you have to like them, it doesn't mean you're minimizing any harms they might cause, or that you're giving those harms a pass. What it does do is replenish your own heart so that you have the energy and focus needed to continue fighting against injustice - including any injustices that person is causing. You're simply better positioned to do that if you can see and extend compassion to other people's suffering - allowing you to get back to your work (including efforts to undo the damage they're causing) more quickly.

To draw on the practice in this way, you think of someone you are angry at, going through a list of things that, just like you, the person wants -to be happy, healthy, loved, etc. To even do this, you might have to imagine the person as a tiny newborn baby. Then there is a list of suffering that, just like you, the person has gone through. Finally, you wish for them (and everyone) to be happy and fulfilled. Perhaps if they were happy and fulfilled, they might be less likely to hold tightly to problematic viewpoints, policies, systems. And if nothing changes with them, something may still shift with you and you'll come to a better way of working with (or against!) them. You can find an example of a "Just like me" practice here.

\section{Question 3 (Appreciating the Good Stuff): Gratitude practice}

A gratitude practice is a straightforward way to recognize and enjoy the positives in life. You just take some time each day to reflect on things you were grateful for or appreciated that day, something beautiful you saw, someone who was kind or (per our earlier example) passed by with a smile. You can keep it open, so that you reflect on any, say, three things. Or try some topics, like one thing you noticed in nature, one thing a loved one did that you appreciated, and one thing you enjoyed. Structure the practice however you want: Do it by yourself or with a partner; write it down or just think it; do it each morning or every night. My recommendation would be to get a small, beautiful notebook and a favorite pen, and write down your three things every night. Here's one set of gratitude journal suggestions. An alternative (or supplement) would be to carry with you (or put on your desk or bedside table) a small smooth "gratitude" stone and when you touch or see it, think of the things you are grateful for. 


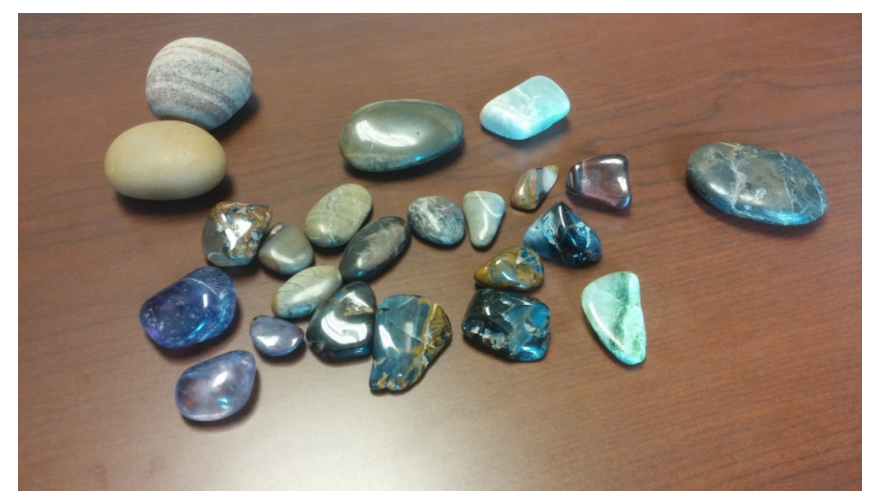

A collection of small, shiny, smooth touchstones laying on a brown table.

\section{Surprise! Probably the most important practice and it's beneficial for all the questions- Sitting meditation}

Plain old sitting meditation is useful in addressing all the questions discussed... and more. If you haven't done sitting practice before, the first thing to know is that you're not expected to - and you don't have to be able to- stop your thoughts. It's also important to note that if you want to start a practice and are dealing with trauma, it may be wise to practice under the care of a trusted meditation teacher, therapist or doctor.

A consistent meditation practice decreases anxiety. During our practice, we let anxieties and emotions come up, see them for what they are (the product of a mind that endlessly thinks) and let them go. If they won't go, we just give the original anxiety some space without layering onto it. Sitting practice also develops the ability to focus, because 1) we're less anxious and 2) focus is literally what we are practicing - noticing when our mind wanders and bringing it back to our chosen focus - our breath and posture. Like any other skill, this one is strengthened through repetition. Being able to focus and notice is crucial to all the questions.

Sitting addresses each of the questions discussed above, starting with assessing our reactions and triggers.

When we sit, we become aware of our self-talk; those are the thoughts you "hear" coming up — which you may also start to notice throughout the day. You don't have to do what they say; you can actually hear them rather than reacting impulsively to something that is not fully conscious. This is what the "wait" part of Question 1 addresses. Sitting also helps us notice patterns; we might notice response patterns or relationship patterns online that are similar to what we do offline.

Through sitting, we recognize when we are starting to react because we're more awake, more present in our bodies. We realize when we are not hearing the other person and only thinking of what we want 
to say (more self-talk!). Consistent practice also helps depersonalize negative stimuli that we're exposed to online; you may not emotionally react to negative stuff with fear or anger, or if you do react, it will help you see your emotions arising and let them go.

And we can make better decisions because we have a fuller understanding of the actual situation - not some story about it that we cooked up in our head. Sometimes you'll realize that the person online is just stressed out and whatever they're saying is really their issue and is not about you (again, this is not always the case and we are not recommending ignoring abuse, injustice or danger).

Sitting also helps us navigate and respond skillfully to our righteous anger.

Learning about and working with injustices that bring up anger can be painful. We worry about others, despair about things that can't be undone, become traumatized when attacked for justice work. We may have PTSD, be in pain, unable to sleep well, feeling sadness, depression and loss. All of these can be helped with a consistent meditation practice.

Meditation also helps us become more compassionate. We understand that everyone just wants to be happy, even though they/we go about it in some very odd, and, yes, problematic and harmful, ways. We become less judgmental. Oddly, this is because we begin to make friends with ourselves. When we do, we make friends with others as well because we see their struggles and imperfections reflected in our own.

Finally, sitting helps us appreciate the positive stuff.

A consistent meditation practice is one of the few things that can raise our "happiness set point." We have a typical level of happiness and when great things happen, our level goes up for a while but returns to the set point. When terrible things happen, same thing; we'll be sadder for a while but eventually return to our typical level. 


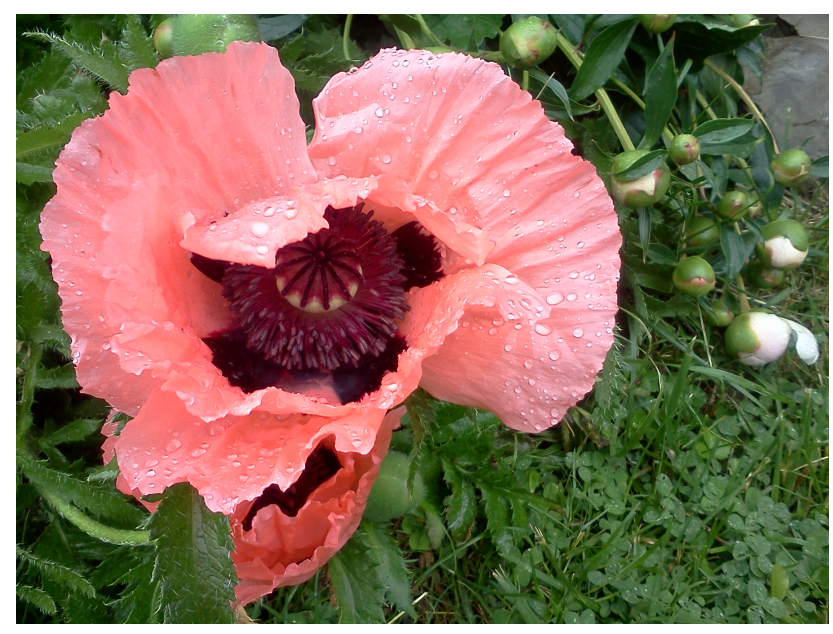

Gratuitous beautiful image of raindrop-bespeckled heart-shaped salmon-colored poppy with a backdrop of peony buds, grass, and clover.

As meditators, we're consistently happier, partly because we actually notice the moments in our lives and partly because we appreciate them. We're more aware of beauty, and yes, also pain and sadness, but since we have a way to feel pain fully and let it go, we don't get stuck in it. We may notice a bird cutting across the sky, a breeze, a toddler thrilled about stomping in a rain puddle. And you'll stay with them longer, appreciating them because you'll be better able to focus your attention; you won't get distracted from that beautiful sunset or a compliment you received.

Final thought about the benefits of sitting meditation for the three questions: It doesn't matter whether your meditation practice on any given day was pleasant or not, you felt inner peace or had a busy mind, you were jarred by memories or you were able to follow your breath; when you sit consistently, you may notice the changes mentioned here.

There are lots of sitting meditation instructions out there; here are a few examples.

And these are mine (from my chapter in the book The Weight of my Armor):

Take an upright position so that your lower body is stable and your upper body is uplifted, feeling as though you have a string pulling you up. The back of the neck is long but the heart is lifted. Your eyes can be open or closed; hands can be resting on your thighs or in your lap. Begin to follow the outbreath, taking a couple of deep breaths to come into your practice. And as you begin following the outbreath, you may notice a thought arising, you may hear a sound, an impulse may come up. Whatever arises, acknowledge it fully without judgment, neither chasing after it nor pushing it away, and returning, when you are able, to your outbreath, a sense of your posture, and just a sense of being in the present moment, which is, after all, where we are. 
As Parts 1 and 2 have emphasized, there's lots to be angry about online, intensified by all the ways that social media sets us up to feel as angry as possible about as much as possible, all to ensure we're as reactive (and thus as active on-site) as possible. Reactivity might be good for social platforms - that's part of their basic business strategy - but it isn't good for us; it's not good for our health, and it undermines our ability to respond skillfully to the causes of our anger. Right now, more than ever, we need to stay healthy, and we need to stay in the fights that desperately need fighting. So, by all means -be angry. But do it mindfully, for your own sake as much as everyone else's.

\section{Acknowledgements}

We'd like to thank Averi Davis and the Syracuse Office of Undergraduate Research and Community Engagement whose SOURCE Grant funded Averi's research assistance. 